\title{
Portfolio scheduling: an integrative approach of limited resources and project prioritization
}

\author{
Félix Villafáñez ${ }^{a}$, David Poza ${ }^{a^{*}}$, Adolfo López-Paredes ${ }^{a}$, Javier Pajares ${ }^{a}$ and Fernando Ace- \\ bes $^{\text {a }}$
}

${ }^{a}$ INSISOC - University of Valladolid, Spain

\begin{tabular}{l}
\hline C H R O N I C L E \\
\hline Article history: \\
Received: December 22019 \\
Received in revised format: De- \\
cember 272019 \\
Accepted: December 282019 \\
Available online: \\
December 282019 \\
\hline Keywords: \\
Project Management \\
Multi-Project Scheduling \\
Portfolio Management \\
Portfolio Scheduling \\
Project Prioritization
\end{tabular}

\author{
A B S T R A C T
}

\begin{abstract}
The main issue for portfolio managers is to find a feasible schedule that guarantees the availability of the resources required by the activities at the dates they are scheduled, which is the classical objective of the Resource-Constrained Multi-Project Scheduling Problem (RCMPSP). This paper goes one step further and presents an algorithm that solves the RCMPSP where each project has a different priority for the organization. With this information, the algorithm uses a market-based mechanism to determine what activities should receive preferential treatment during the scheduling process. Therefore, among the multiple possible schedules that comply with the resource constraints (i.e. the solution provided by classical approaches to RCMPSP), our approach allows obtaining a schedule for the portfolio in which, beyond minimizing the duration of the portfolio, the activities are scheduled considering the portfolio manager's priorities.
\end{abstract}

\section{Introduction}

Project-Based firms organize their operations through projects (Artto \& Kujala, 2008) regardless of whether they are internal (i.e. capital investment projects) or external (i.e. customer delivery projects). These companies must simultaneously manage internal and external projects, large and small projects, and unique and repetitive projects (Gareis, 1991). Consequently, new challenges emerge for managers, and new project management methods are required to manage multiple projects competing for resources and financial support (Engwall \& Jerbrant, 2003). Maylor et al. (2006) evidence the "projectification of the firm". Taking data from a survey, they argue that while projects are the basic organizational elements in companies, programs and portfolios of programs are the current mechanisms for managing organizations. In this context (managing multiple projects), a main challenge is to define a clear process to handle priorities within projects (Platje \& Seidel, 1993): the project leaders will compete for resources and, to avoid conflicts and crisis, the general management should focus on setting priorities, authorizing the portfolios and resolving bottlenecks. Platje and

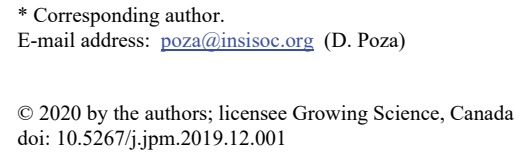


Seidel (1993) already stated that the portfolio-management team will need new tools to make explicit the tradeoffs between conflicting interests by calculating the feasibilities of the various configurations for the portfolio. Caniëls and Bakens (2012) claim, as Gareis (1991) did two decades ago: there is a demand for software that can provide a more realistic approach for resource allocation and activities scheduling so that portfolio managers can simulate different portfolio configurations.

In this context, the aim of this paper is to present an algorithm for multi-project scheduling that provides a feasible schedule (considering resource constraints) in which the total duration of the portfolio is minimized while considering the priority allocated by the portfolio manager to each project within the portfolio in the scheduling process.

The rest of the paper is organized as follows: In Section 2, we present a background on project scheduling and Portfolio Management. Section 3 focuses on the description of our approach in which we integrate multi-project scheduling and the consideration of the portfolio manager's priorities in the scheduling process. Section 4 describes the functioning of the algorithm. In Section 5, we discuss the contributions of our work and provide an example of the application of the algorithm. Finally, we present the conclusions of this paper.

\section{Background on project scheduling and Portfolio Management}

Project scheduling is a branch of Project Management whose objective is to find a date for project activities in which a set of constraints hold. Project scheduling is in fact a major issue for companies facing rapid changes in its environment (Demeulemeester et al., 2013). One of these constraints is considering that the execution of project activities consumes resources while there is a limited number of shared resources available for the execution of the project activities. Obtaining a schedule in which all the resources required for the execution of an activity are available at the date that activity has been scheduled is not a trivial task (Hartmann \& Briskorn, 2010). So much so that it became a line of research in Project Management's literature under the name of Resource-Constrained Project Scheduling Problem (RCPSP) (Herroelen, 1972).

RCPSP was proven to be, in terms of Complexity Theory, a NP-Hard problem in strong sense, which implies that obtaining the optimal solution by means of the traditional techniques proposed by Operational Research is not possible in a polynomial time (Blazewicz et al., 1983). Despite this, researchers have struggled to develop new methods to obtain feasible (yet maybe not optimal) project schedules in which this resource constraint holds (Habibi et al., 2018). Some authors proposed applying linear techniques such as Integer Linear Programming (ILP) or Mixed Integer Linear Programming (MILP) (Demeulemeester \& Herroelen, 2002). Regardless of the applied technique, any solution of the RCPSP provides a feasible project schedule in which there are no conflicts among the resources shared by the project activities.

However, in general terms, companies do not normally manage one single project with shared resources, but a set of projects whose execution requires sharing some company's resources among activities from different projects (i.e. a project portfolio). This multi-project problem obviously increases the difficulty of the scheduling process far beyond the RCPSP. The research on scheduling techniques for the multi-project case was given the name Resource-Constrained Multi-Project Scheduling Problem (RCMPSP) (Davis \& Patterson, 1969). Several proposals were made to solve the RCMPSP as an Integer Linear Programming, ILP (Toffolo et al., 2016) or a Mixed Integer Linear Programming, MILP (Kyriakidis et al., 2012) but, as in the single project case, this problem cannot be resolved in a direct way as it is also considered an NP-Hard problem in strong sense (Villafáñez et al., 2018).

Given the difficulties in finding the optimal solution for the RCPSP / RCMPSP with ILP and MILP formulations, researchers recently explored new ways of dealing with project / portfolio scheduling by means of heuristics and metaheuristics (Villafáñez et al., 2019), which provided sufficiently 
satisfactory (yet not optimal) results. They may be based on techniques such as ant colony optimization algorithms (Majazi \& Ranjbar, 2012), simulated annealing (Fink \& Homberger, 2013), multiagent systems (Zheng et al., 2014), genetic algorithms (Pérez et al., 2015; Habibi et al., 2018), combinatorial auctions (Song et al., 2016; Villafáñez \& Poza, 2010) or even negotiation mechanisms (Homberger \& Fink, 2017).

Regardless of the resolution approach, the advances in the research on multi-project scheduling are giving as a result in new algorithms that provide a feasible schedule in an environment in which several projects compete for the same resources, which are often referred to as global resources (Villafáñez et al., 2018). However, sharing resources among projects is only one of the issues companies face in a real environment. In practice, companies that manage multiple projects simultaneously must adapt their structure (portfolios and portfolios of programs) and their resources to meet the contractual objectives of scope, schedule, costs, quality and satisfaction of their stakeholders. These companies make an effort to ensure that projects are in line with the company's strategy, yielding what is known as Project Portfolio Management (Turner, 1999; Martinsuo, 2013).

In this context, there exists a lot of research on management techniques for project selection criteria (Doerner et al., 2006; Kaiser et al., 2015; Henriksen \& Traynor, 1999; Kavadias \& Loch, 2003; Zuluaga et al., 2007; Cooper et al., 2000; Olson \& Wu, 2010; Ghassemi \& Amalnick, 2018). These criteria may be defined in the interest of the business success (Meskendahl, 2010), aligning the portfolio to improve the performance (Dooley et al., 2005), balancing the resources across the portfolio (Engwall \& Jerbrant, 2003), considering investment decisions (Birge, 2007) or minimizing the risk for investors (Yu et al., 2010). Once the projects that will form part of the portfolio have been selected, not all of the projects will normally have the same priority for the company (Cooper et al., 1997). Several authors have proposed methods to determine what projects within the portfolio are a priority for the company (Koc et al., 2009; Ghasemzadeh et al., 1999; Simão et al., 2018; Hannach et al., 2016). Due to the conflicts that arise when many projects use the same critical resources (Laslo \& Goldberg, 2008), projects may need to be re-prioritized by a higher strategic management level by making decisions that include re-allocation of resources (Jonas, 2010).

Despite the academic achievements and software developments in the last decades, project executions continue to present time and cost overruns (Herroelen, 2005). The introduction of uncertainty in classical methods, both in in project scheduling (Herroelen \& Leus, 2005; Demeulemeester \& Herroelen, 2007; Lambrechts et al., 2008) and project planning and control (Pajares \& LópezParedes, 2011; Acebes et al., 2014) contributes to provide a more realistic approach to project management operational issues.

In this paper we propose to integrate project prioritization in the resource constrained multi-project scheduling problem (RCMPSP) to find a feasible schedule compatible with the priorities assigned by the portfolio manager while we ensure an optimal allocation of (global) constrained resources to reduce the total duration of the portfolio (makespan).

\section{Method: a market-based approach for the allocation of resources in multi-project scheduling}

In multi-project scheduling some of the resources required for the execution of the activities are shared by several projects (Villafáñez et al., 2018). If the portfolio manager decides to assign a higher priority to a given project, there must be set a mechanism that favors the scheduling of the activities that belong to that project.

A trivial solution would be to establish a strict hierarchy by sorting the projects in descending order of priority $\left(\mathrm{P}_{\mathrm{j}}>\mathrm{P}_{\mathrm{k}}>\ldots . .>\mathrm{P}_{\mathrm{w}}\right)$ so that the activities that belong to $\mathrm{P}_{\mathrm{j}}$ are scheduled in the first place, then the activities that belong to $\mathrm{P}_{\mathrm{k}} \ldots$ and eventually the activities that belong to $\mathrm{P}_{\mathrm{w}}$. This option generates significant inefficiencies in the use of resources and increases the total duration of the portfolio unnecessarily. 
We propose to use the efficiency of the markets to solve allocation problems, in this case, allocation of resources to activities. Each project will be endowed with some funding (according to the priority it has been assigned) that gives the chance to acquire the resources it needs. The price of the resources will vary according to the punctual demand. In this way, when several activities compete for a resource, the activity with the 'highest reserve price' will be able to acquire the resource and consequently be scheduled whereas the other activity (activities) will be postponed until the resource is released.

In this market, the price of each resource unit at a given time comes from the difference between the supply (i.e. the number of available units of that resource at that time) and the demand for that resource (i.e. the number of units of that resource requested by all the projects in the portfolio at that time). If a resource is highly demanded at a particular time, its price will be relatively high. This means that only the projects with the highest funding (i.e. prioritized projects) will be able to acquire that resource at that time. When a project achieves the resources it needs, the activity that required those resources will be scheduled, and the resulting price of those resources will be subtracted from the project's budget. On the other hand, when the resources needed by an activity cannot be bought because the project to which it belongs has an insufficient budget at that time, the schedule of that activity will be postponed until that project can afford the acquisition of that resource.

We would like to remark that the price a project must pay to acquire the resource required by an activity does not correspond to the real execution cost of that activity. In our approach, we use funding as the underlying mechanism that drives the prioritization. This means that this funding does not correspond to the real project's funding requirements (which can be calculated once the portfolio schedule has been obtained). We use funding as an artifice to 'pay' for the resources required by the activities (whose price is determined by the internal market on a supply and demand basis).

This mechanism allows the portfolio manager to select and evaluate different scenarios to prioritize the projects. In Figure 1 we present four options to do this:

- Funding curve a). The portfolio manager allocates enough funds to cover $k$ times the total planned cost of the project $C_{\max }\left(P_{j}\right)$ from the beginning: $k \cdot C_{\max }(P j)$

- Funding curve $b$ ). The portfolio manager allocates enough funds to cover the total planned cost of the project $C_{\max }\left(P_{j}\right)$ from the beginning.

- Funding curve c). The portfolio manager allocates the funds to cover the total planned cost of the project $C_{\max }\left(P_{j}\right)$ providing the funding in different moments during the project lifecycle, but always providing enough funds to cover the planned cost along the project lifecycle.

- Funding curve d). The portfolio manager allocates the funds to cover the total planned cost of the project $C_{\max }\left(P_{j}\right)$ providing funds in different moments during the project lifecycle although the funding curve is below the project cost baseline.

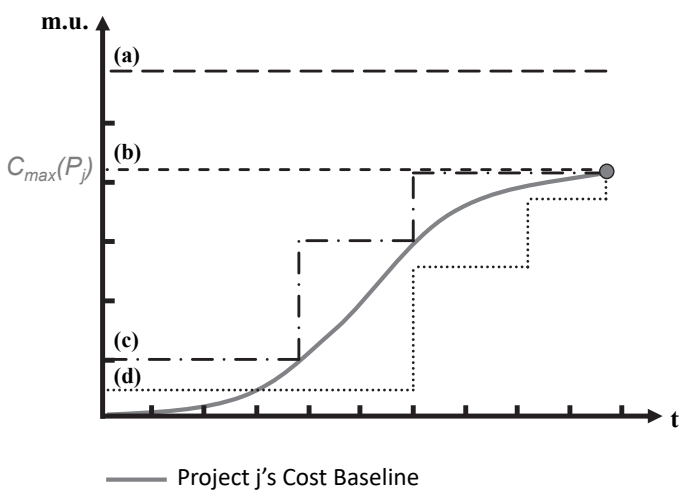

Fig. 1. Four options to select the funding (i.e. priority) of the project $j$ within the portfolio (mu: monetary units) 
Following an analogy with project funding, in our approach, the profile of the funding curves represents the availability of funds to pay the scheduling prices of the activities. Therefore, its shape will condition the moment and the amount of resources that can be allocated to the project. Since in our approach the scheduling of an activity will require to 'pay' a scheduling price (which will depend on how valuable that resource is according to the internal market created by the algorithm), it is necessary to ensure a sufficient amount of money at the moment the activity is scheduled to pay the scheduling price of that activity. If the funds are not available at that time, the activity will need to be scheduled at a later moment at which the project has obtained the necessary funds for the acquisition of the resources required by the activity.

Each project within the portfolio will have some funding, which will be taken as input for the scheduling process in our algorithm. This funding will determine how easy it is for a project to acquire the resources needed by the activities.

It is common that some projects within the portfolio have a higher priority for the company. In a practical situation, the portfolio manager may want to allocate a higher budget to those projects to accelerate its execution (i.e. to facilitate an early completion of the schedule of those projects). Our approach can be used to prioritize some projects within the portfolio by means of the allocation of higher or lower funds to the projects depending on their priority.

\section{Implementation}

We consider that the portfolio's time horizon is split into several indivisible units that we will call time-slots. These units can be any temporal magnitude (days, weeks, months, etc.). The duration of the activities, the project and the portfolio will be measured in time-slots.

Each resource $k$ has a certain number of units available per time-slot $(t)$, which we will call resourceunits. It is important to mention that the resource-units are indistinguishable and, therefore, interchangeable. Consequently, at a particular time-slot, all the units of the same resource will have the same price. The actual number of resource-units of the resource $k$ available at the time-slot $t$ will be referred to as resource availability $\left(\mathrm{r}_{\mathrm{k}, \mathrm{t}}\right)$. In addition, we will use the term resource capacity $\left(\mathrm{r}_{\mathrm{k}-\mathrm{max}}\right)$ to describe the maximum number of resource-units available per time-slot for the resource $k$. Figure 2 illustrates the concepts of time-slot $(\mathrm{t})$, resource-unit, resource availability $\left(\mathrm{r}_{\mathrm{k}}\right)$ and resource capacity $\left(\mathrm{r}_{\mathrm{k}-\mathrm{max}}\right)$.

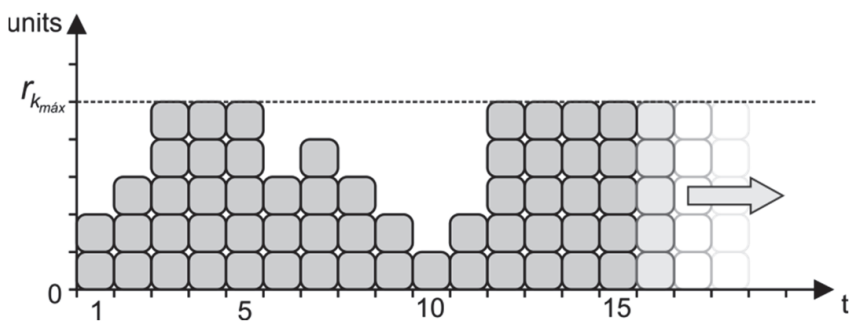

Fig. 2. Concepts of time-slot, resource-unit, resource capacity and resource availability

The graph shows the availability of the resource $k$ in time-slots 1 to $15\left(\mathrm{r}_{\mathrm{k}, \mathrm{t}} \mathrm{t} \in[1,15]\right)$. The dotted line shows the resource capacity ( $\mathrm{r}_{\mathrm{k}-\mathrm{max}}=5$ units). The actual availability of this resource $\left(\mathrm{r}_{\mathrm{k}}\right)$ is represented as the number of piled cubes in each time-slot. For example, although the capacity of this resource is $\mathrm{r}_{\mathrm{k}-\mathrm{max}}=5$ units, its actual availability at time-slot 1 is 2 resource-units $\left(\mathrm{r}_{\mathrm{k}, 1}=2\right)$ because presumably the other three resource-units have already been allocated to other activities of the portfolio. Our approach is based on a case of the RCMPSP known as SMRCMPSP (SingleMode Resource-Constrained Multi-Project Scheduling Problem). In single-mode scheduling, it is considered that activities have a fixed duration and a fixed number of resources required for its execution (whereas in multi-mode scheduling, activities can be executed with different durations depending on the number of allocated resources). We also consider that activities cannot be interrupted once they have started. Therefore, in our implementation, for an activity to be scheduled, it must have enough funds to acquire the entire set of resource-units it requires during the whole 
duration of the activity. Consequently, the entire disbursement on resources will occur at the timeslot when the activity begins. The scheduling process starts once the portfolio manager has defined the funding curves for each project, which are taken as an input. This process is composed of a succession of iterations, which we will call scheduling-steps. There will be as many schedulingsteps as necessary until all the activities in the portfolio have been scheduled. Fig. 3 shows a flowchart of the algorithm.

The main actions will be:

1. Generate a preliminary schedule for the activities that have not been yet scheduled.

2. Calculate the demand for resources and update the resource's supply.

3. Calculate the price of the resource-units in the current scheduling-step.

4. Retrieve the current balance for each project.

5. Create a list of prioritized candidate activities.

6. Attempt to schedule the candidate activities of the current scheduling-step

\section{- Step 1. Generate a preliminary schedule for the activities that have not been yet scheduled}

The schedule is composed of two types of activities: activities whose schedule is definitive (because they were definitively scheduled in a previous scheduling-step) and activities whose schedule is temporary (because it is not guaranteed that the resources they need are available at those provisional dates).

First, the activities with a definitive starting date (if any) are placed in the schedule. Notice that the dates of these activities will not undergo any changes during the rest of the scheduling process. Then, their successors are added to the schedule. The scheduling of the successors is temporary and is based on the Critical Path Method (CPM), in which the constraints associated with the consumption of resources are ignored. The dates of these activities will become definitive if the following two conditions (which will be checked in later steps) meet. First, all the resources needed by the activities must be available during the whole duration of the activities. Secondly, the project to which an activity belongs must have enough funds to acquire all the resources required by that activity.

\section{- Step 2. Calculate the demand for resources and update the supply of resources}

For each resource, a demand curve is built on the theoretical amount of resources required by each activity according to the provisional schedule created in step 1 . The supply of resources is based on the current availability of resources (i.e. they depend on the resource's maximum capacity and the number of resource-units that have already been allocated to other activities already scheduled).

\section{- Step 3. Calculate the price of the resource-units in the current scheduling-step}

For each resource (k), and for each time-slot (t), we compare the number of resource-units required by the activities (i.e. resource demand, $\mathrm{D}_{\mathrm{k}, \mathrm{t}, \mathrm{s}}$ ) and the available number of resource-units (i.e. resource supply, $\mathrm{S}_{\mathrm{k}, \mathrm{t}, \mathrm{s}) \text {. }}$

The market-based mechanism embedded in the algorithm generates a price for each resource-unit in every time-slot $\left(\mathrm{p}_{\mathrm{k}, \mathrm{t}, \mathrm{s}}\right)$. This price is calculated by modifying the price it reached in the previous scheduling-step ( $\left.\mathrm{p}_{\mathrm{k}, \mathrm{t}, \mathrm{s}-1)}\right)$ by certain amount (Araúzo et al. 2010). This amount is proportional to the difference between the demand and the supply of that resource in that time step. In order to obtain the price of the resource-unit $k$ in the time-slot $t$ for the scheduling-step $s$, we proceed as shown in Eq. (1). 


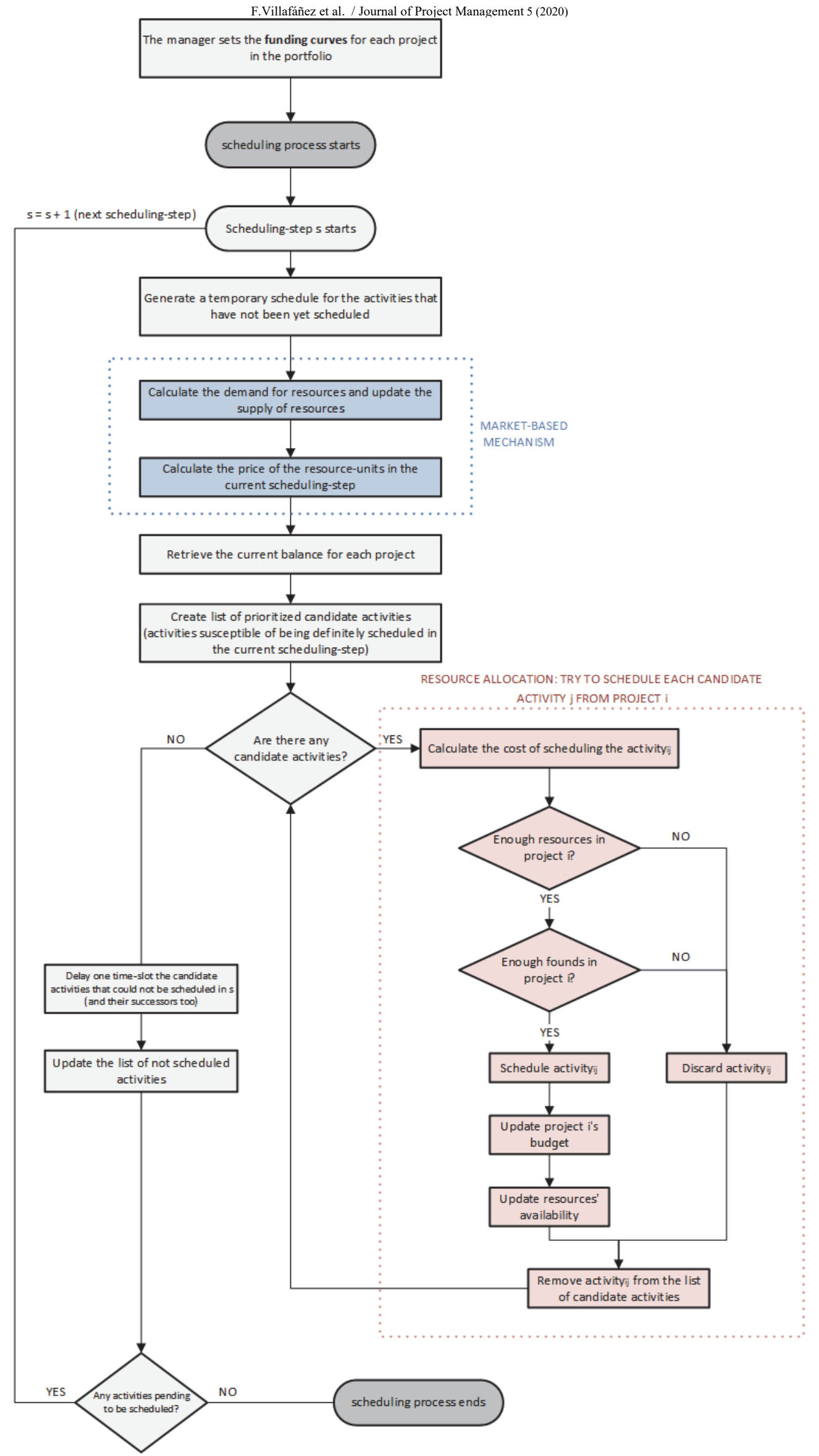

Fig. 3. Flowchart of the algorithm 
Equation 1. Calculation of the price of each resource-unit $\mathrm{k}$ in the time-slot $\mathrm{t}$ during the scheduling-step s.

The parameter $\lambda$ represents the increment in the price of a resource-unit between two consecutives scheduling-steps. This provokes an increase in the price of the resource-units located in time-slots where the demand is higher than the supply. Consequently, the greater the difference between the demand and the supply, the higher the increase in the price raise. On the contrary, in those cases where the demand is lower than the supply, the price of the resources will go down.

The prices obtained for the time-slots in a concrete scheduling-step will only be valid for that scheduling-step, as they will be recalculated in subsequent scheduling-steps. Note that the prices for the same resource-unit $\mathrm{k}$ in the same time-slot will normally change in every scheduling-step $\left(\mathrm{p}_{\mathrm{k}, \mathrm{t}, \mathrm{s}} \neq\right.$ $\left.p_{k, t, s+1}\right)$ due to changes in the demand and the supply of resources as the activities are definitely scheduled.

\section{- Step 4. Retrieve the current balance for each project}

Each project's current balance will be used to acquire the resources needed for their activities. Each project's initial balance corresponds to the funds allocated by the portfolio manager to that project. However, that balance will change over time: they may fall as the project activities are scheduled (as it requires spending money on resources) or they may rise due to new cash inflows at particular dates defined by the portfolio manager.

\section{- Step 5. Create a list of prioritized candidate activities}

By candidate activities, we mean those activities with no predecessors or activities whose predecessors have already finished. In other words, they are the subset of activities (of any of the projects in the portfolio) that are susceptible of being definitely scheduled in the current scheduling-step.

Once this list is obtained, we must establish an order in which the candidate activities will be tried to be scheduled. To this aim, we use the priority rule-based heuristic introduced in Villafáñez et al. (2019). First, we try to schedule the activity with the minimum total slack. Since it is possible that several activities have the same total slack, we use a second priority rule that breaks the ties randomly.

\section{- Step 6. Attempt to schedule the candidate activities of the current scheduling-step}

We try to schedule each candidate activity, one by one, following the steps below:

First, we check whether the resources needed by the activity are available. If they are not, that activity is immediately discarded. If all the resources required by the activity are available, the scheduling process continues. Secondly, we calculate the scheduling price of each activity, as the sum of the acquisition prices of the resources needed for the execution of that activity. The acquisition price of a resource is calculated as the number of required resource-units multiplied by the price of each resource-unit along the time-slots in which that resource is needed. As a matter of example, let the activity $i j$ (i.e. the activity $j$ from the project $i$ ) be the activity whose scheduling price we need to calculate. Let $d_{i j}$ be the duration of that activity. Let us assume that there are $K$ resources involved in the execution of this activity. Let $r_{i, j, k, t}$ be the number of resource-units of the resource $K$ required by the activity $i j$ at the time step $t$. The scheduling price of this activity is calculated as shown in Eq. 2: 
$\sum_{k=1}^{K} \sum_{t=0}^{d i j} r_{i, j, k, t} \cdot p_{k, t, s}$

Equation 2. Calculation of the scheduling price of an activity.

Once the scheduling price is calculated, we check if the project $i$ has enough balance to cover the scheduling cost of the activity $i j$. Note that the disbursement of money is to be done at the moment the activity $i j$ starts. If the balance is enough, the activity $i j$ will be definitely scheduled and the scheduling cost will be subtracted from the budget of project $i$. Since the activity $i j$ has been scheduled, the resource-units allocated to that activity will disappear from the market, which will result in a decrease of the supply of that resource. On the other hand, if the project's balance was not enough to pay for the scheduling price, the activity is discarded.

In the next scheduling-step, a new temporary scheduling will be built on the results of the current scheduling-step. All the candidate activities that could not be scheduled in the current schedulingstep (either because the resources required were not available or because the project's budget was not enough), will be delayed one time-slot in that provisional schedule. Consequently, the successors of those activities will also undergo the subsequent delay. The scheduling process continues until the scheduling of all the activities is definitive.

During the scheduling process, the market-inspired mechanism embedded in the algorithm calculates a scheduling price for each activity (Equation 2), which depends on the price of the resources required by the activity at that particular time during the scheduling process, which, in turn depends on the demand - number of projects that require the same resource - and the supply - number of resource-units available at that time. It should be taken into account that this scheduling price is not the cost associated with the execution of the activity. This price is an artifice that allows calculating how 'valuable' a resource is at a specific time. Consequently, in case of a resource conflict (i.e. if there are not enough resource-units available for all the projects requesting them) the algorithm allocates the resource to the projects that 'value that resource the most'. How much a project 'values' a resource is also a market metaphor: this value is the project's amount of funds available at that time for the acquisition of the resource, which in essence depends on the funding assigned to that project by the portfolio manager in the beginning of the scheduling process. Consequently, since the scheduling prices are an artifice, so is the funding provided by the portfolio manager. That is to say, if the portfolio manager assigns a higher amount of funds to a project to obtain a schedule that prioritizes its completion, these funds do not need to be the actual funds for the execution of the project: they simply need to be relatively higher than the funds assigned to other projects in the portfolio that are not a priority.

Obtaining the real funding required for the execution of the portfolio is beyond the schedule of this study. However, its calculation is immediate. Once the portfolio manager has obtained a feasible schedule that is in line with her priorities, she simply needs to consider that schedule and the real costs associated to the execution of the activities to obtain a portfolio cost baseline. From this information, she will simply need to find a (real) funding that is compatible with the desired schedule.

\section{Discussion: project portfolio scheduling with market-based prioritization}

The approach presented in this paper provides a feasible schedule in which the duration of the portfolio is minimized while considering the priorities of the projects within the portfolio. By using the funding curves to represent the different priorities of the projects, the portfolio manager obtains a schedule that is in line with the priorities of the organization. Let us remember that the possibility of an activity being scheduled depends on the current amount of funds of the project to which it belongs. Therefore, providing a project with a relatively higher amount of funds will increase the probability of its activities being scheduled. 
This functionality may be used by the portfolio manager to test how different allocation of funds affects the scheduled obtained for the portfolio. If the portfolio manager is not satisfied with the schedule obtained for the portfolio, she can allocate a new set of funding curves to the projects and obtain different schedules.

In this paper we have used an extension of the heuristic-based algorithm for multi-project scheduling presented in Villafáñez et al. (2019). The performance of this algorithm was validated with all the testing problems collected in the library MPSPLib (Homberger 2007). The novelty is that project priorities are now considered during the scheduling process. The portfolio manager can select the projects' relative priority by allocating a relatively higher funding to the priority projects. It should be noted that if we provide an unlimited funding scheme to every project in the portfolio (i.e. all the projects receive the same amount of money - greater than the maximum cost for every project from the beginning) we will obtain the results presented in Villafáñez et al. (2019).

We will use a very simple case from MPSPLib to show that our algorithm provides the expected prioritization results, while the criteria used in MPSPLib to rank the best algorithms Total Makespan (TMS) and Average Project Delay (APD) both remain with good values. The portfolio is shown in Figure 4 and consists of five projects, with 30 activities each. We represent each project as a horizontal bar indicating its duration and its start/end dates. For simplicity, we have chosen a portfolio comprised of the repetition of the same project five times with certain delay between the starting dates of each project. If we take Project 1 as a reference, the starting date of the other four projects are delayed 4, 9, 16 and 20 time-units, respectively. This figure shows the critical-path duration (CPD) of the five projects (i.e. the duration of the projects assuming that all the resources required will be available at the times required by the activities).

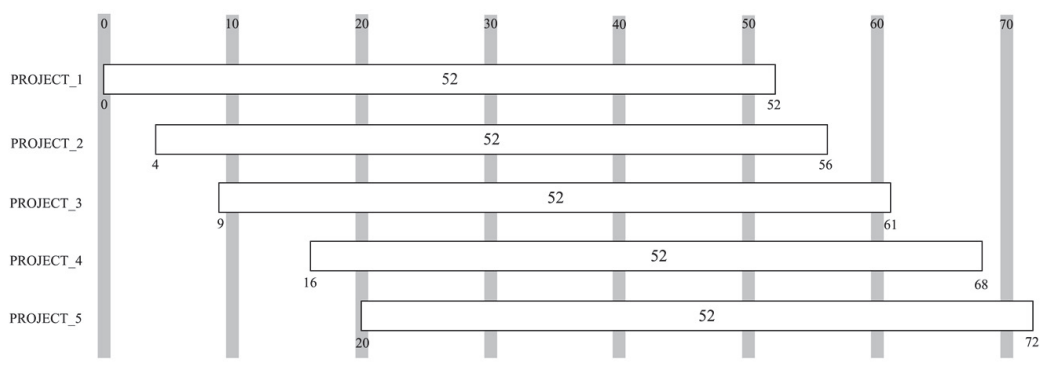

Fig. 4. Critical-path duration (CPD) of the five projects that comprise the portfolio

Due to the limitation in the number of resources, this schedule is not feasible. Fig. 5 shows the resulting schedule after the application of resource leveling by means of the algorithm proposed by Villafáñez et al. (2019). Since this algorithm does not consider prioritization, it simply provides a feasible schedule for the portfolio with a minimum makespan.

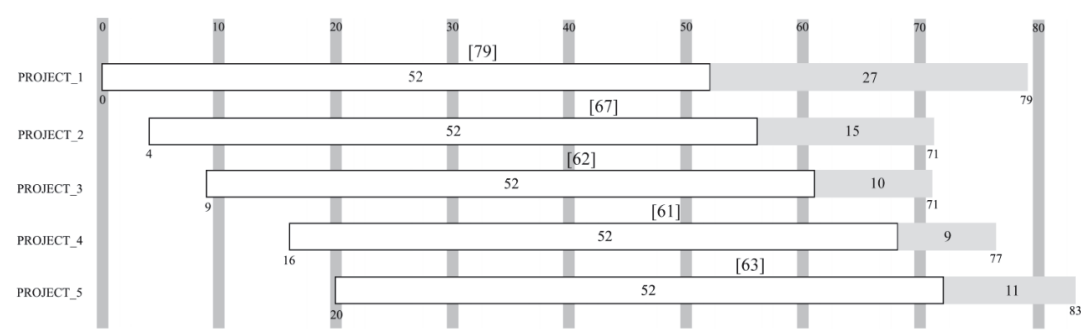

Fig. 5. Schedule provided by the algorithm proposed by Villafáñez et al. (2019) in which prioritization is not considered

We will now use our approach to find a feasible schedule in which the portfolio duration is minimized while considering the priorities of the five projects. As previously discussed, the portfolio manager is to use the projects' funding curves to establish a profile that is in accordance with the company's priorities. We will perform two experiments, in each of which different priorities for 
the company will be considered. In the first experiment, we will assume that Project 3 is a priority for the company. In order to favor the scheduling of Project 3's activities over the activities of other projects, we will assign a relatively higher budget to this project. Fig. 6 shows the funding curves used in the first experiment.

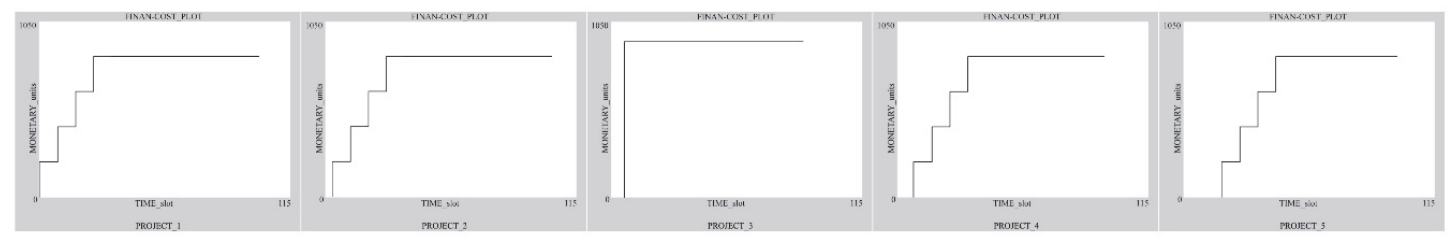

Fig. 6. Funding curves defined in the first experiment. Project 3 is given a high funding to accelerate its schedule

In the second experiment, we switch the prioritization from Project 3 to Project 4, whereas the other projects in the portfolio have the same funding as applied in the first experiment. Figure 7 shows the funding curves used in the second experiment.

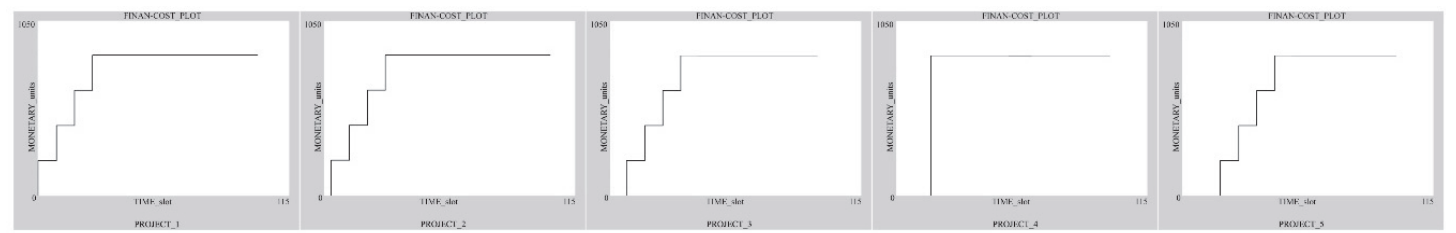

Fig. 7. Funding curves defined in the second experiment. Project 4 is given a high funding to accelerate its schedule

Fig. 8 shows a comparison of the schedules obtained in the two experiments. Due to the resource constraints, the actual duration (makespan) of the five projects obviously becomes longer after the scheduling process. In both experiments, the portfolio manager obtains a feasible schedule for the whole portfolio in which the duration of the whole portfolio is minimized. The particularity of our approach (beyond other algorithms for the RCMPSP) is that the project manager will obtain different feasible schedules for the portfolio depending on the (fictitious) funds allocated to each project, which represents to what extent each project is a priority for the company.

In the first experiment (top of Fig. 8), if we compare the original critical-path duration of each project and their actual duration after the scheduling process, we observe that Project 3 (i.e. the project to which the portfolio manager has assigned a higher amount of funds) achieves a relatively fastest execution (61 time-units). On the other hand, in the second experiment (bottom of Figure 8), in which the portfolio manager has assigned more funds to Project 4, we observe that Project 4 obtains the fastest execution (60 time units) as desired by the portfolio manager.
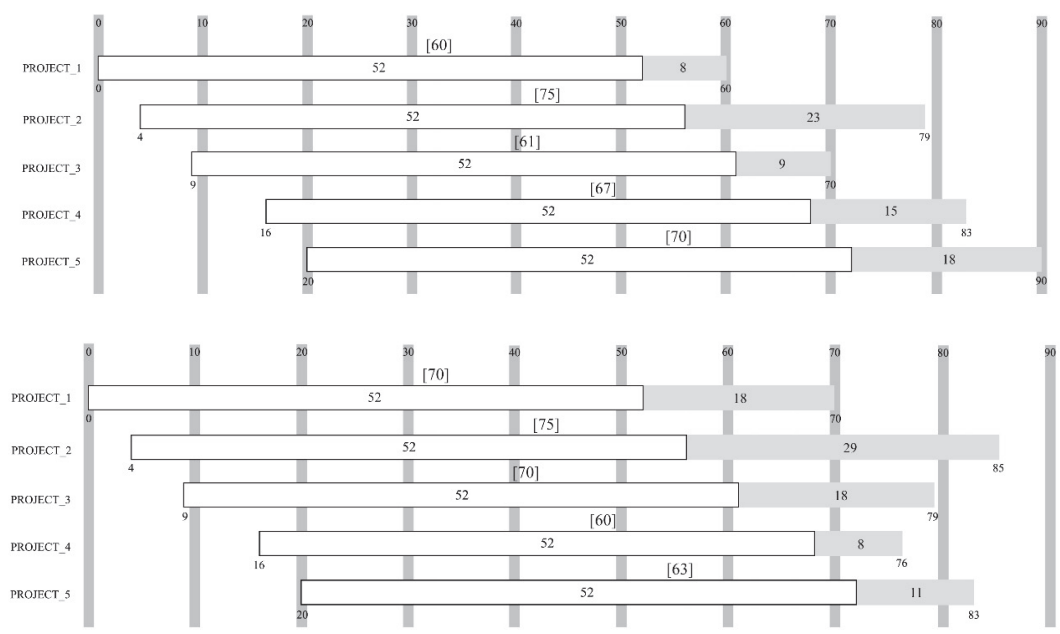

Fig. 8. Comparison of the schedules obtained in the two experiments 
Our approach can be used as a simulation tool in which the portfolio manager can obtain different schedules depending on the priorities (i.e. funding) allocated to each project. In all cases, the total makespan of the portfolio will be minimized. To do that, the portfolio manager simply needs to select different funding curves (as the curves shown in Fig. 6 or Fig. 7) until she achieves a schedule in which the projects are prioritized according to the specific needs of the company. The algorithm proposed in this paper will also provide the schedule shown in Fig. 5 when all the projects are endowed with the same sufficiently high funding (which would indicate that all the projects have the same priority).

\section{Conclusions}

Despite the multiple mechanisms available to obtain feasible schedules in multi-project scheduling (RCMPSP) and the abundant literature on criteria to prioritize projects within an organization, there are currently no scheduling tools that allow portfolio managers to obtain schedules that consider the organization's priorities in the scheduling process. The algorithm that we have presented in this paper exploits a market metaphor to solve the resource allocation within the projects in a portfolio while considering the company's priorities. The peculiarity of this algorithm is that it incorporates project prioritization during the scheduling process. Before the scheduling process starts, the portfolio manager determines what projects are more urgent for the organization. With this information, the algorithm creates an artificial market that permits scheduling the activities belonging to those projects with a higher priority. Consequently, the proposed approach provides feasible schedules for a portfolio (in which its total duration is minimized) while gives the portfolio manager the opportunity to test the impact of changing priorities in the company on the portfolio schedule.

\section{Acknowledgments}

This research has been partially financed by the project ABARNET (Agent-Based Algorithms for Railway NETworks optimization) financed by the Spanish Ministry of Economy, Industry and Competitiveness with grant DPI2016-78902-P; the project "Lonja de Impresión 3D para la Industria 4.0 y la Empresa Digital (LONJA3D)" funded by the Regional Government of Castile and Leon and the European Regional Development Fund (ERDF, FEDER) with grant VA049P17; and the project "Nuevos modelos computaciones en Ingeniería de organización: Sistemas de Soporte a la decisión basados en Agentes (SSDBA)" with reference INSISOC-FUNGE/063/160011.

\section{References}

Acebes, F., Pajares, J., Galán, J. M., \& López-Paredes, A. (2014). A new approach for project control under uncertainty. Going back to the basics. International Journal of Project Management, 32(3), 423-434.

Araúzo, J. A., Pajares, J., \& Lopez-Paredes, A. (2010). Simulating the dynamic scheduling of project portfolios. Simulation Modelling Practice and Theory, 18(10), 1428-1441.

Artto, K., \& Kujala, J. (2008). Project business as a research field. International Journal of Managing Projects in Business, 1(4), 469-497.

Birge, J. R. (2007). Optimization methods in dynamic portfolio management. Handbooks in Operations Research and Management Science, 15, 845-865.

Blazewicz, J., Lenstra, J. K., \& Kan, A. R. (1983). Scheduling subject to resource constraints: classification and complexity. Discrete Applied Mathematics, 5(1), 11-24.

Caniëls, M. C., \& Bakens, R. J. (2012). The effects of Project Management Information Systems on decision making in a multi project environment. International Journal of Project Management, 30(2), 162-175.

Cooper, R. G., Edgett, S. J., \& Kleinschmidt, E. J. (1997). Portfolio management in new product development: Lessons from the leaders-I. Research-Technology Management, 40(5), 16-28.

Cooper, R. G., Edgett, S. J., \& Kleinschmidt, E. J. (2000). New problems, new solutions: making portfolio management more effective. Research-Technology Management, 43(2), 18-33.

Davis, E. W., \& Patterson, J. H. (1969). An exact algorithm for the multiple constrained project scheduling problem. Yale University. 
Demeulemeester, E. L., \& Herroelen, W. S. (2002). Scope and Relevance of Project scheduling. Project Scheduling: A Research Handbook, 1-11.

Demeulemeester, E., \& Herroelen, W. (2007). Introduction to the special issue: project scheduling under uncertainty. Journal of Scheduling, 10(3), 151-152.

Demeulemeester, E., Kolisch, R., \& Salo, A. (2013). Project management and scheduling.

Doerner, K. F., Gutjahr, W. J., Hartl, R. F., Strauss, C., \& Stummer, C. (2006). Pareto ant colony optimization with ILP preprocessing in multiobjective project portfolio selection. European Journal of Operational Research, 171(3), 830-841.

Dooley, L., Lupton, G., \& O'Sullivan, D. (2005). Multiple project management: a modern competitive necessity. Journal of Manufacturing Technology Management, 16(5), 466-482.

Engwall, M., \& Jerbrant, A. (2003). The resource allocation syndrome: the prime challenge of multi-project management?. International Journal of Project Management, 21(6), 403-409.

Fink, A., \& Homberger, J. (2013). An ant-based coordination mechanism for resource-constrained project scheduling with multiple agents and cash flow objectives. Flexible Services and Manufacturing Journal, 25(1-2), 94-121.

Gareis, R. (1991). Management by projects: the management strategy of the 'new'project-oriented company. International Journal of Project Management, 9(2), 71-76.

Ghasemzadeh, F., Archer, N., \& Iyogun, P. (1999). A zero-one model for project portfolio selection and scheduling. Journal of the Operational Research Society, 50(7), 745-755.

Ghassemi, A., \& Amalnick, M. (2018). NPD project portfolio selection using reinvestment strategy in competitive environment. International Journal of Industrial Engineering Computations, 9(1), 47-62.

Habibi, F., Barzinpour, F., \& Sadjadi, S. (2018). Resource-constrained project scheduling problem: review of past and recent developments. Journal of Project Management, 3(2), 55-88.

El Hannach, D., Marghoubi, R., \& Dahchour, M. (2016, March). Project portfolio management Towards a new project prioritization process. In 2016 International Conference on Information Technology for Organizations Development (IT4OD) (pp. 1-8). IEEE.

Hartmann, S., \& Briskorn, D. (2010). A survey of variants and extensions of the resource-constrained project scheduling problem. European Journal of operational research, 207(1), 1-14.

Henriksen, A. D., \& Traynor, A. J. (1999). A practical R\&D project-selection scoring tool. IEEE Transactions on Engineering Management, 46(2), 158-170.

Herroelen, W. (2005). Project scheduling-Theory and practice. Production and Operations Management, 14(4), 413-432.

Herroelen, W., \& Leus, R. (2005). Project scheduling under uncertainty: Survey and research potentials. European Journal of Operational Research, 165(2), 289-306.

Herroelen, W. S. (1972). Resource-constrained project scheduling - the state of the art. Journal of the Operational Research Society, 23(3), 261-275.

Homberger, J. (2007). A multi-agent system for the decentralized resource-constrained multi-project scheduling problem. International Transactions in Operational Research, 14(6), 565-589.

Homberger, J., \& Fink, A. (2017). Generic negotiation mechanisms with side payments-Design, analysis and application for decentralized resource-constrained multi-project scheduling problems. European Journal of Operational Research, 261(3), 1001-1012.

Jonas, D. (2010). Empowering project portfolio managers: How management involvement impacts project portfolio management performance. International Journal of Project Management, 28(8), 818-831.

Kaiser, M. G., El Arbi, F., \& Ahlemann, F. (2015). Successful project portfolio management beyond project selection techniques: Understanding the role of structural alignment. International Journal of Project Management, 33(1), 126-139.

Kavadias, S., \& Loch, C. H. (2003). Optimal project sequencing with recourse at a scarce resource. Production and Operations Management, 12(4), 433-444.

Koc, A., Morton, D. P., Popova, E., Hess, S. M., Kee, E., \& Richards, D. (2009). Prioritizing project selection. The Engineering Economist, 54(4), 267-297.

Kyriakidis, T. S., Kopanos, G. M., \& Georgiadis, M. C. (2012). MILP formulations for single-and multimode resource-constrained project scheduling problems. Computers \& Chemical Engineering, 36, 369385 .

Lambrechts, O., Demeulemeester, E., \& Herroelen, W. (2008). Proactive and reactive strategies for resourceconstrained project scheduling with uncertain resource availabilities. Journal of Scheduling, 11(2), 121136. 
Laslo, Z., \& Goldberg, A. I. (2008). Resource allocation under uncertainty in a multi-project matrix environment: Is organizational conflict inevitable?. International Journal of Project Management, 26(8), 773-788.

Majazi Dalfard, V., \& Ranjbar, V. (2012). Multi-projects scheduling with resource constraints \& Priority rules by the use of Simulated Annealing Algorithm. Tehnički vjesnik, 19(3), 493-499.

Martinsuo, M. (2013). Project portfolio management in practice and in context. International Journal of Project Management, 31(6), 794-803.

Maylor, H. , Brady, T. , Cooke-Davies, T. , \& Hodgson, D. (2006). From projectification to programmification. International Journal of Project Management, 24, 663-674.

Meskendahl, S. (2010). The influence of business strategy on project portfolio management and its successa conceptual framework. International Journal of Project Management, 28(8), 807-817.

Olson, D. L., \& Wu, D. (2010). Portfolio Selection Under Fuzzy and Stochastic Uncertainty. In Enterprise Risk Management Models (pp. 171-183). Springer, Berlin, Heidelberg.

Pajares, J., \& Lopez-Paredes, A. (2011). An extension of the EVM analysis for project monitoring: The Cost Control Index and the Schedule Control Index. International Journal of Project Management, 29(5), 615621.

Pérez, E., Posada, M., \& Lorenzana, A. (2016). Taking advantage of solving the resource constrained multiproject scheduling problems using multi-modal genetic algorithms. Soft Computing, 20(5), 1879-1896.

Platje, A., \& Seidel, H. (1993). Breakthrough in multiproject management: how to escape the vicious circle of planning and control. International Journal of Project Management, 11(4), 209-213.

Simão Filho, M., Gomes, U. R. P., \& Pinheiro, P. R. (2018, June). Project portfolio prioritization aided by verbal decision analysis. In 2018 13th Iberian Conference on Information Systems and Technologies (CISTI) (pp. 1-6). IEEE.

Song, W., Kang, D., Zhang, J., \& Xi, H. (2016, May). Decentralized multi-project scheduling via multi-unit combinatorial auction. In Proceedings of the 2016 International Conference on Autonomous Agents \& Multiagent Systems (pp. 836-844). International Foundation for Autonomous Agents and Multiagent Systems.

Toffolo, T. A., Santos, H. G., Carvalho, M. A., \& Soares, J. A. (2016). An integer programming approach to the multimode resource-constrained multiproject scheduling problem. Journal of Scheduling, 19(3), 295307.

Turner, J. Rodney. The handbook of project-based management. Vol. 2. London: McGraw-Hill, 1999.

Villafáñez, F., Poza, D., López-Paredes, A., Pajares, J., \& del Olmo, R. (2019). A generic heuristic for multiproject scheduling problems with global and local resource constraints (RCMPSP). Soft Computing, 23(10), 3465-3479.

Villafáñez, F. A., Poza, D., López-Paredes, A., \& Pajares, J. (2018). A unified nomenclature for project scheduling problems (RCPSP and RCMPSP). Dirección y Organización, 64, 56-60.

Villafáñez, F., \& Poza, D. J. (2010). Propuesta de Modelo MAS para la resolución del RCMPSP basado en Subastas Combinatorias. Best practices in project management. Methodologies and case studies in construction and engineering. INSISOC, Valladolid, Spain.

Yu, M., Takahashi, S., Inoue, H., \& Wang, S. (2010). Dynamic portfolio optimization with risk control for absolute deviation model. European Journal of Operational Research, 201(2), 349-364.

Zheng, Z., Guo, Z., Zhu, Y., \& Zhang, X. (2014). A critical chains based distributed multi-project scheduling approach. Neurocomputing, 143, 282-293.

Zuluaga, A., Sefair, J. A., \& Medaglia, A. L. (2007, April). Model for the selection and scheduling of interdependent projects. In 2007 IEEE Systems and Information Engineering Design Symposium (pp. 1-7). IEEE.

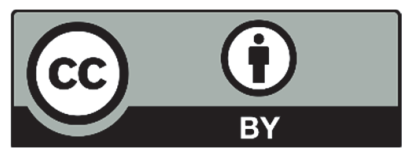

(C) 2020 by the authors; licensee Growing Science, Canada. This is an open access article distributed under the terms and conditions of the Creative Commons Attribution (CC-BY) license (http://creativecommons.org/licenses/by/4.0/). 